\title{
Aspects regarding the capitalization of remanufactured scrap in the automotive industry using a Paternoster system
}

\author{
C Torcătoru ${ }^{1}$, D Săvescu ${ }^{2}$ \\ ${ }^{1,2}$ Product Design, Mechatronics and Environment Department, Transilvania University of \\ Braşov, Romania \\ E-mail: constantin.torcatoru@unitbv.ro
}

\begin{abstract}
Among the current challenges of the global automotive industry include changes in global markets that lead to a variety of products, regulation that drives pressure on new technologies, and competition from new competitors. This paper attempts to find answers to the question, how can we capitalize the semi-finished parts of the automotive industry that have emerged from the parameters demanded/imposed by the final customer or which have some visual / design defects, but which retain their functional role. In almost all cases, information and communication technology plays a major role in future strategies to meet the challenges mentioned above, which can stimulate the production process more efficient by using intelligent manufacturing approaches. Thus, this paper proposes to automate and maximize the capitalization of these parts, a Paternoster system for eliminating the logistics/storage space, reducing the handling time, increasing the efficiency and traceability of the scrap.
\end{abstract}

Keyword: automotive industry, advanced technologies

\section{Introduction}

In this paper, we try to find answers to the question of how we can maximize the use of remnants of the automotive industry in this era of advanced technologies, for trying to rebuild the parts with certain visual or design defects but retaining the role functional is a very old subject, even in the period immediately following the start of production. This problem has arisen even in traditional craftsmanship when our trees have realized that some of these products have defects, some of which are major, and can't be used for the purpose for which they were created.

With the passing of the years, the manufacture of products has evolved from handicraft to mechanical, automated.

Vehicles represent the pursuit of freedom of each individual. The relevance of the car industry to economic prosperity and its impact on jobs can be seen in all major areas of the market and countries. Interestingly, both developed and developing countries see this industry as the backbone for their own economy.

The automotive industry has wide-ranging effects across the economy, supporting a vast supply chain and generating a range of business services. In the European Union, 19.6 million automobile units are produced annually, the turnover generated by this sector accounting for $6.8 \%$ of EU GDP. [4] This sector employs around 13.3 million people or $6.1 \%$ of the workforce in the EU. Approximately 3.4 million jobs in the automotive industry account for $11.3 \%$ of EU employment. [4] The automotive 
industry is the largest private investor in R \& $\mathrm{D}$ in Europe, with nearly $€ 54$ billion invested annually. In 2017, over 8400 patents were granted to the automotive sector by the EPO. Worldwide, 98.9 million vehicles were produced in 2017.

A paternoster or paternoster elevator is an elevator for passengers consisting of a chain of open compartments, which moves slowly and without interruption in a loop up and down, inside a building. The same method is used for the storage cabinets that store large amounts of paper documents or small parts. [8]

Paternoster name ("Our Father", the first two words of the Lord's prayer in Latin) was first applied to this device because the lift is in the form of a loop and is similar to rosary beads used as an aid in reciting prayers. [9]

Peter Ellis installed the first lifts that could be described as a paternoster lift in Oriel Chambers in Liverpool in 1868. [6] In 1877, British engineer Peter Hart has obtained a patent for the first paternoster [1]. In 1884, in Dartford, England, the engineering firm of J \& E Hall installed its first "Cyclic Lift", using Hart's patent, in a London office building. [5]

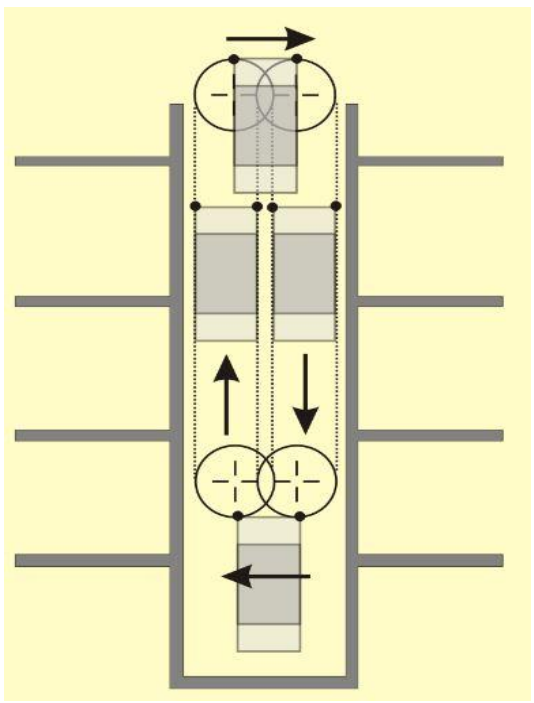

Figure 1. The 2D scheme of a Paternoster

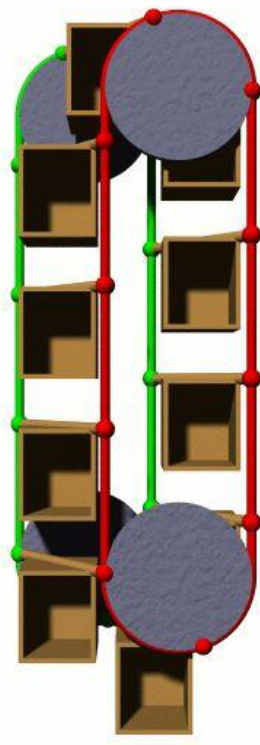

Figure 2. The operating principle of paternoster,[Source: Own work, author RokerHRO, 20.01.2019]

Paternosters lifts were popular during the first half of the twentieth century because they could carry more passengers than ordinary elevators. These were more common in continental Europe, especially in public buildings than in the UK. They are relatively slow elevators usually traveling at about $30 \mathrm{~cm} / \mathrm{sec}$ (about $1 \mathrm{ft} / \mathrm{sec}$ ) to facilitate starting and stopping. [11]

With the passage of time and the emergence of new technologies, this system has begun to grow and be developed in several areas, reporting on the first occurrence.

Lately, these systems have been developed in many areas and in various forms, based on the principle of operation of the first paternoster systems. [2]

\section{Literature review}

The automotive industry comprises a very wide range of companies and organizations in the design, development, manufacture, marketing, and sales of motor vehicles, being one of the largest economic sectors in the world. 


\subsection{Series production in the automotive industry}

Manufacturing or manufacturing process is meant the physical or chemical transformation of materials, substances or components into new products or components through a series of processes.

The British Encyclopedia [3] mentions that "manufacturing is an industry that makes raw material products by using manual labor or machines, usually routinely carried out with the division of labor."

Manufacturing as a system of design processes and the sequence of actions needed to produce the product as it was conceived and designed in order to solve a problem or meet a need.

As can be seen in Figure 3, at the beginning of this year 2019, the European automotive market registered a slower start, with a decline of $4.6 \%$ over the previous year. [5]

This effect can be felt throughout the manufacturing sector in the automotive industry, and in the case of small producers, it is already becoming an alarming situation, for which they have to resort to various fireworks, such as reducing the number of employees, increasing the range of products, new smart technologies etc

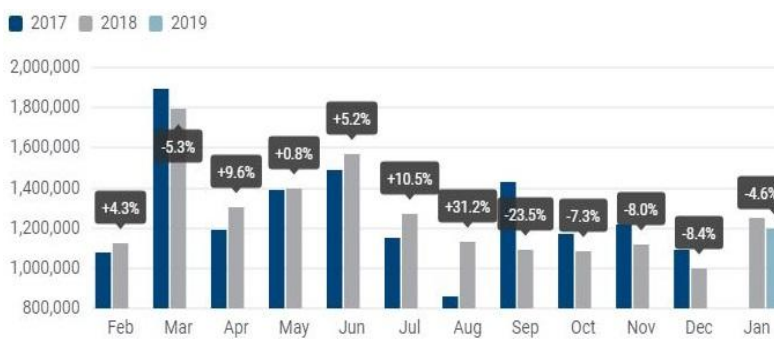

Figure 3. Car production in the UE, 2019 versus 2018. [Source: ACEA, 2019]

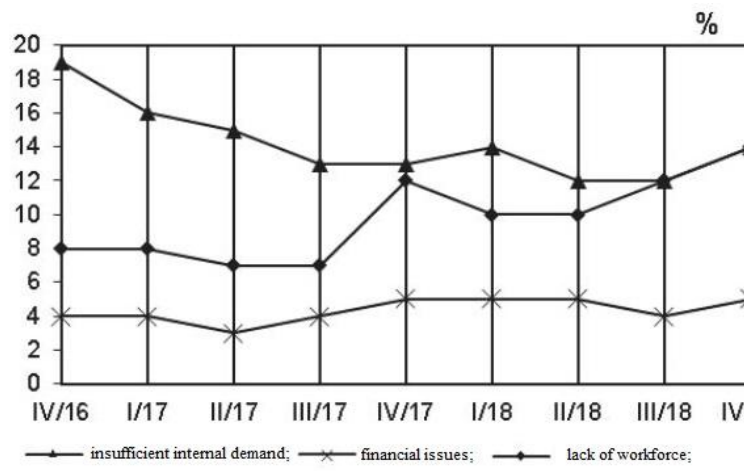

Figure 4. The main causes of production limitation

In Romania, according to the managers' opinions, the main causes limiting the processing activity are (Figure 4):

- Insufficient internal demand (14\% of total cases);

- Lack of workforce (14\% of total cases);

- Financial issues (5\% of total cases).

\subsection{General classification for parts of the automotive industry}

Depending on the customer relationship criteria, the types of manufacturing can be structured into the following categories:

- manufacture on stock;

- custom manufacturing;

- mixed manufacturing.

There are many companies that combine the first two types and have mixed manufacture for strategic or competitive considerations. For example, the desire to be a unique manufacturer in its product line can lead a stock company to complete its catalog of offers by offering custom-made products. The desire to compete on a delivery rate criterion can motivate a custom-made manufacturing company to store key components and subassemblies by offering larger quantities of custom-made assembly. Receipt of an order initiates assembly and finishing product based on the customer's specifications.

Depending on the way of obtaining, the products from the automotive industry can be obtained:

- by injection of plastics; 
- by machining (forging, casting, cutting processing, cold pressing, etc.)

- by sewing;

- by quilting; "cașerare";

- by pasting etc

\subsection{Paternoster system}

Paternoster is an excellent solution for optimal downtime. The particular reduction in collection time is seen in the sorting of batches, offering a quicker recovery.

The paternoster type system is very used in the storage/logistics area, for the simple fact that space is saved, the handling time of the objects placed in the paternoster cabins/containers decreases and the efficiency of the management used is increased.

There are storage machines, vending machines, as storage systems and computer-controlled transfer that significantly improve storage efficiency and processing of products.

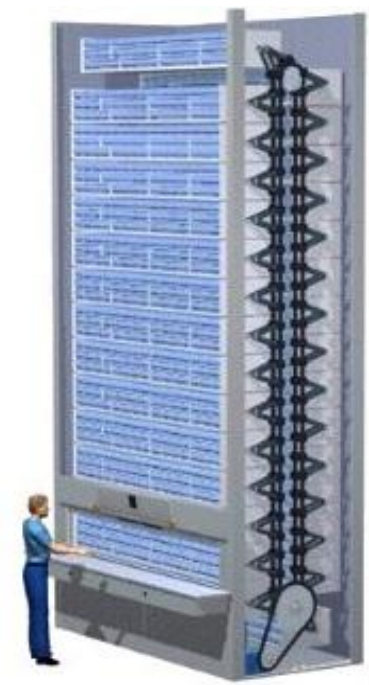

Figure 5. Operation of a paternoster

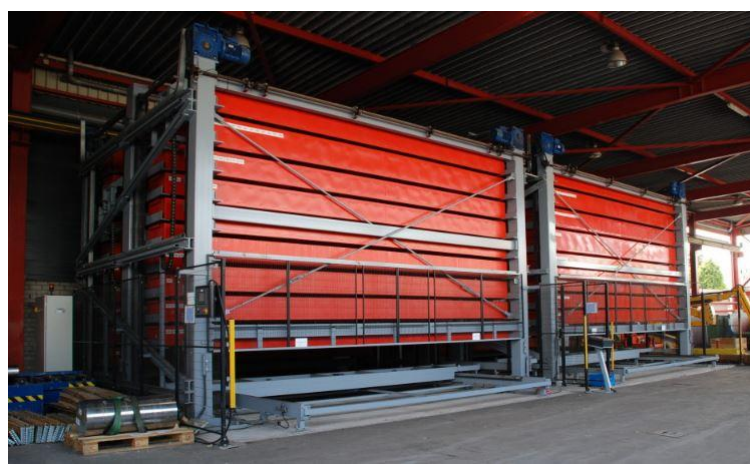

Figure 6. Paternoster system for large products

As can be seen from Figure 5, according to Paternosterkast, an automatic storage system saves up to $70 \%$ of the storage space, reduces choice errors and decreases the lifting time by more than $60 \%$. The most efficient way to use the storage machine is to include warehouse management in the machine. This is suitable for use with a variety of storage systems such as storage machines, small parts racks, and pallet racks. [7]

These paternoster storage systems are currently used for both bulk and bulk products as well as bulky and heavy products. For example, in Figure 6, there is presented a paternoster system used for storage/logistics of products with large dimensions and masses, such as semi-finished products made of laminated bars or steel blocks. This system is equipped with 34 containers, and a container can be loaded up to a maximum weight of 4 tons, the entire system can be loaded with up to 136 tons of products. The same type of system can be seen in Figure 5, but with smaller dimensions and can be used in case of small products.

Control of these systems is permanently made from a computer that can be connected to a managed internet source such as SAP.

\subsection{Quality and risk management for rebut items}

Manufacturing process management- MPM is a process of defining and managing the manufacturing processes that will be used to manufacture, assemble, and perform the final product inspection. [12] 
MPM is a process by which the manufacturing industries will use different types of technology to help produce products with different machine locations and different ways in which assembly lines could be placed. Production engineers use CAD data to define the different processes through which the new product will be manufactured. The MPM system is used to develop the sequence of operations, machine location planning, production line balancing and 3D design of human and robotic operations, as well as the delivery of machine programs and electronic work instructions at workshops. Production engineers assess different manufacturing scenarios, material flows, calculate production costs and the effects of changes on production lines. [13]

Statistical process control is a quality control method that uses statistical methods to monitor and control a process that produces serial products, such as a manufacturing process. Using this control during the manufacturing process makes it possible to determine whether the process is being carried out normally by providing only compliant products. Obtaining the necessary information for a statistical control is done by sampling n-size samples at defined time intervals and verifying one or more quality characteristics of the objects or elementary sampling units in order to ascertain whether during the manufacturing process these characteristics do not change significantly.

When applying statistical control, it is necessary to be able to act on the process by making appropriate adjustments to ensure that a normal process is carried out.

When applying statistical process control, the main tools are the control sheets, the Pareto diagram, the design of the experiments.

At statistical control, objects in the sample can be controlled by:

- quantitative, measurable characteristics such as dimensional dimensions; these variables are often distributed after the Gauss normal distribution, but a Poisson, binomial, etc. distribution is also possible;

- qualitative or attributive features such as the appearance of the product,

- the number of defects in the sample or the number of defects per sample elementary unit.

Another method used in quality analysis and control is the FMEA (Failure Mode and Effects Analysis), described as a procedure for product development and management of potential failure analysis operations under a fault probability classification system and which continues 3 main objectives:

- identifying and assessing the risk of potential product failure, flexible manufacturing system, and failure effects;

- Identification of actions that could eliminate or reduce the likelihood of a potential breakdown and development of control plans;

- Documenting the flexible manufacturing system and risk management;

Another way of analyzing product quality, from the design stage, is a more complex methodology, called DFMA (Design for Manufacture and Assembly), to provide guidance to the design team to simplify product structure, reduce manufacturing costs, assemble and quantification of improvements. In the practice of applying DFMA, the emphasis is on identifying, quantifying and eliminating unnecessary or redundant or ineffective elements in designing the product. [14]

DFMA focuses on three main directions:

- Reducing the number of components (parts, subassemblies) of an assembly;

- Redesigning simpler, modular components, easier to process and control, and even cheaper;

- Optimization of production and control technologies;

A product scrap, seen as a whole unit or unit is defined as a product resulting from the manufacturing process, which does not meet the quality set by standards, internal rules, contracts etc. and which can't be used directly for the purpose for which it was realized, representing an economic loss. A product considered to be a rebuttal following the manufacturing process can be recovered using a reshaping method to be brought to the quality set by the qualitative and standard conditions or can be recovered without intervening with any change to it, finding the defect by selling at a low price to less demanding customers. 


\section{Discussion}

The longer the production line, the more it requires a larger number of people, processes and, of course, a longer time. The more people are needed, the higher the mistakes, the scrapping rate.

Therefore, we can see once again how the company loses money by paying extra people's wages, storing stocks, raw materials by repairing defective products, etc. It is not at all an appropriate solution to simply replace old machines with new ones, but replacing old machines with new ones that do not require human involvement (or require minimal involvement or supervision, although a worker who stays and looks at a machine does not add value) is a much more effective solution and, most likely and important, is a long-term solution.

It can be said that lately, eliminating the human operator from as many places on the production line has become a prime concern and even a "trend" in the idea of stopping as much as possible from the errors of the human operator.

Lately, many companies are very focused on the "zero defects" concept, but as nothing in this world is perfect, rebate products are always on the line of production due to the desire to increase the volume of products and to be in the prime plan with what's happening in the market. Technologically, it can be said that in many cases it is possible to achieve the "zero defect" target. However, it is a difficult threshold to overcome, large firms with high investment potential, accept the best $98 \%$ of good products. A target of $99 \%$ involves extremely high costs, much higher than $2 \%$ non-conforming products.

Focusing heavily on increasing product volumes, many manufacturers neglect more or less noncompliant products. Very few wonder what happens to scrapes that can mostly be reused after a reshuffle. If the costs of handling, storing, logistics of these scrapes were calculated, it would be economical and a substantial gain. In general, the criteria for classification for defects are analogous to the criteria for classifying the quality characteristics:

- nature - functional and structural, appearance, packaging;

- measurement possibilities (measurable / attributive);

- importance - critical, major, minor;

- after effect - allowing reshuffle;

- after the moment of occurrence, related to the product's lifetime: youth, maturity, old age;

- the character of occurrence: accidental; systematic;

- by cause, origin, the most important criterion for the removal of their occurrence;

Depending on the causes, defects fall into one of the six factors, namely: material, worker, machine, working method (technology), measurement, environment.

\subsection{Suggestions for capitalizing remanufactured scrap}

- Referring to scrapes that have appearance defects but which retain their functional role, they can be capitalized without interfering with their modification, reshaping them.

For example, there are manufacturers that produce components for the interior of cars. These components result from machining operations such as injection molding, hot pressing, sewing, gluing, taping, etc. For various reasons, defects such as lack of material in certain areas of the product, a bulge in a certain area, seams defects (deformed stitch, ruptured sewing material, "rare mesh", material wrinkling, seams missing etc.), discoloration of the material after the soldering operation, burns and scratches resulting from the make-up operation etc.

By reporting on the automotive industry, these products that have certain appearance defects can be redeemed by selling the final product to less demanding customers or to companies that provide certain services (taxi, courier, etc.) but with a re-valued sales cost finding defects.

- Regarding scrapes that have functional defects, but which through a certain reshuffling of the product, I can restore the functional state for which they were created, can be capitalized if the repair costs and the allocated time are small. 
- If we refer to scrapes that have both aesthetic and functional defects, it is not appropriate to remedy them due to high costs, but can be redeemed by using under normal conditions that rebut for another purpose for which it was originally created.

For example, if we think of car safety belts, assuming that for some reasons they do not meet the qualitative standards set by the standards, these rebated belts can be reused for another purpose, such as the use of straps to secure goods in trucks or for palletizing goods.

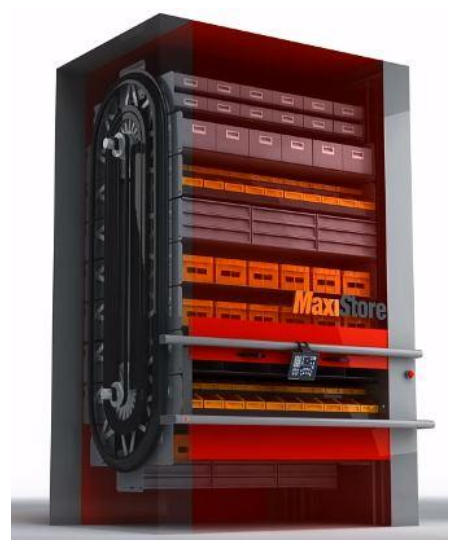

Figure 7. Type of Paternoster by Maxi Store

In Figure 7, there is shown a paternoster system, which is customized with different sizes and shapes of the racks in which the scrap can be stored and sorted, depending on the defect category settings that are introduced into the paternoster computer.

\subsection{Possibilities of implementation of the redeemed scrap in the paternoster system}

Taking into account that at present they are manufacturers in the automotive industry that use up to $90 \%$ of their waste, they are doing it in a classic way, and considering the possibility of implementing a paternoster management / logistics system, would save from the storage space, reduce time and handling costs, manufacturers would have an overview of the scrap for a certain period of time.

In Figure 8, there are exemplified some compartment models that can be customized according to the customer's need and operated manually or automatically (horizontally) to the loading position, to facilitate operator ergonomics and reduce the dead times

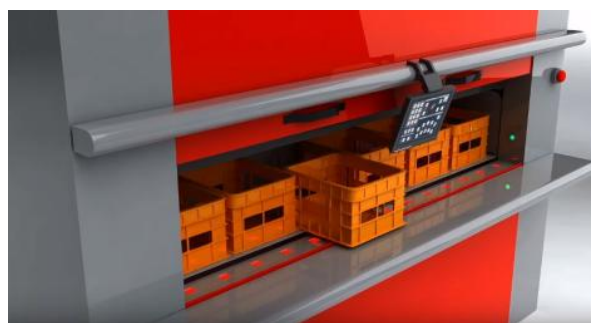

a.

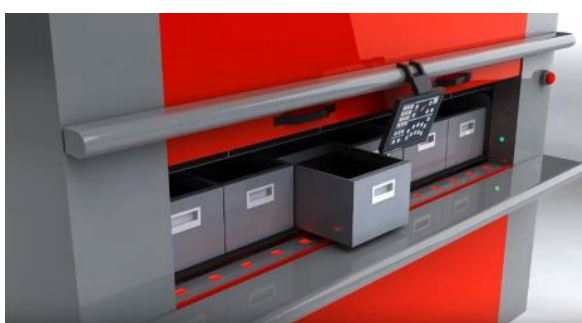

b.

Figure 8. Custom Paternoster by Maxi Store [Source: Youtube.com]

The rebuttable parts can be recorded with the bar code that is unique to each piece. Later, when it is desired to "archive" some rebuttable pieces, it is possible to scan the bar code and somewhere in an observation field to introduce the defects of the product after the evaluation of the Technical and Quality Control Department, then its paternoster system store it on the "district/container" that has a certain defect category. 
On paternoster shelves/containers, defects can be determined from its software, defects categories and subcategories, and when a product with an aesthetic defect is introduced, for example, the system knows where it can store. They can be customized in many ways, for example, depending on the category and severity of the defect, to reassess the value of these scrapes.

Nowadays, the big manufacturers that are in trend with technology, use a system similar to the one mentioned in the consumable products in the idea of recycling materials and reduce the future costs of acquisition. For example, the cutting plates used for machining when worn out are returned by human operators in an automated system that sorts them according to the chemical composition of the tiles, later being sent to manufacturers and reused as raw material.

\section{Conclusion}

Due to the speed of today's technology, it has begun to grow and grow in any field, and the rise in the labor shortage increases the need for technology development.

By implementing such a paternoster system, one of the causes limiting the processing activity, namely the lack of labor, mentioned in subchapter 2.1, would be stopped.

In the following papers, some case studies will be approached regarding the implementation of a Paternoster type system on certain remnants of the automotive industry in Brasov.

The purpose of implementing these systems is to maximize the use of these types of rebuttal, to have a traceability of the production flow trace of the semi-finished parts, to simplify existing procedures and documentation for capitalizing on these products, to reduce costs for sorting, logistics, inventory, storage of said scrap, to automate this process.

\section{References}

[1] Benoit. Bertrand, (25 June 2015), "Is It Time for Germany's Doorless Elevators to Move On?" The Wall Street Journal accessed in December 2018;

[2] "Circulating Multi-Car Elevator System Exponential increase in carrying capacity" accessed in January 2019;

[3] Encyclopedia Britannica accessed in March 2019

[4] Facts about the Automobile Industry accessed in March 2019;

[5] "Hart's Cyclic Elevator Mansion House Chambers - J. and E. Hall". The Engineer: 61. 26 January 1883.

[6] "In the footsteps of Peter Ellis" accessed in January 2019;

[7] "Lift Machine - TORNADO improves efficiency and saves space and time" accessed in March 2019

[8] "Paternosterkast, Bertello" accessed in February 2019;

[9] "Paternoster. dictionarry.oed.com" accessed in December 2018;

[10] "Passenger car registrations, 2019 versus 2018" accessed in March 2019;

[11] Strakosch, George R. (1998). The vertical transportation handbook. Wiley. pp. 99-100. ISBN 978-0-471-16291-9. Accessed in November 2018;

[12] Siciliano, Albert (2009). Improving Manufacturing Process Management with Windchill MPMLink;

[13] Shalvi, Marsha (2003, September) Manufacturing Process Management. A New Era in Manufacturing;

[14] ValterN., Design pentru Fabricatie si Asamblare-notite de curs-Edit. Bren, ISBN987-606-610-2247

[15] Yoon J, Ryu J and Lim K B 2005 A novel reconfigurable ankle rehabilitation robot for various exercises Proceedings of the 2005 IEEE International Conference on Robotics and Automation ICRA 2005 pp 2290-2295

[16] Jamwal PK, Xie S and Aw K C 2009 Kinematic design optimization of a parallel ankle rehabilitation robot using modified genetic algorithm Robotics and Autonomous Systems $57 \mathrm{pp} 1018-1027$

[17] Sze S M 1969 Physics of Semiconductor Devices (New York: Wiley-Interscience) 